\title{
BMJ open Can a psychosocial intervention programme teaching coping strategies improve the quality of life of Iranian women? A non-randomised quasi-experimental study
}

Hamideh Addelyan Rasi, ${ }^{1,2}$ Toomas Timpka, ${ }^{1}$ Kent Lindqvist, ${ }^{1}$ Alireza Moula ${ }^{3}$

To cite: Addelyan Rasi $\mathrm{H}$, Timpka T, Lindqvist $\mathrm{K}$, et al. Can a psychosocial intervention programme teaching coping strategies improve the quality of life of Iranian women? A nonrandomised quasiexperimental study. BMJ Open 2013;3:e002407. doi:10.1136/bmjopen-2012002407

- Prepublication history and additional material for this paper are available online. To view these files please visit the journal online (http://dx.doi.org/10.1136/ bmjopen-2012-002407).

Received 26 November 2012 Revised 28 January 2013 Accepted 22 February 2013

This final article is available for use under the terms of the Creative Commons Attribution Non-Commercial 2.0 Licence; see http://bmjopen.bmj.com

${ }^{1}$ Department of Medical and Health Sciences, Linköping University, Linköping,

Sweden

${ }^{2}$ School of Life Sciences, University of Skövde, Skövde, Sweden

${ }^{3}$ Department of Social and Psychological Studies, Karlstad University, Karlstad, Sweden

Correspondence to Dr Hamideh Addelyan Rasi; hamideh.addelyan.rasi@liu.se

\section{ABSTRACT}

Objectives: To assess whether a psychosocial intervention teaching coping strategies to women can improve quality of life (QOL) in groups of Iranian women exposed to social pressures.

Design: Quasi-experimental non-randomised group design involving two categories of Iranian women, each category represented by non-equivalent intervention and comparison groups.

Setting: A large urban area in Iran.

Participants: 44 women; 25 single mothers and 19 newly married women.

Interventions: Seventh-month psychosocial intervention aimed at providing coping strategies.

Primary outcome measures: Effect sizes in four specific health-related domains and two overall perceptions of QOL and health measured by the WHOQOL-BREF instrument.

Results: Large effect sizes were observed among the women exposed to the intervention in the WHOQOLBREF subdomains measuring physical health $(r=0.68$; $p<0.001)$, psychological health $(r=0.72 ; p<0.001)$, social relationships $(r=0.52 ; p<0.01)$, environmental health $(r=0.55 ; p<0.01)$ and in the overall perception of QOL $(r=0.72 ; p<0.001)$; the effect size regarding overall perception of health was between small and medium $(r=0.20$; not significant). Small and not statistically significant effect sizes were observed in the women provided with traditional social welfare services.

Conclusions: Teaching coping strategies can improve the QOL of women in societies where gender discrimination is prevalent. The findings require reproduction in studies with a more rigorous design before the intervention model can be recommended for widespread distribution.

\section{INTRODUCTION}

Coping strategies help people to deal more effectively with stressful life events and persistent problems, and can eventually increase the quality of their lives. ${ }^{1-3}$ According to

\section{ARTICLE SUMMARY}

Article focus

- To assess whether a psychosocial intervention teaching coping strategies to women exposed to social pressures can improve their health-related quality of life (QOL).

Key message

- Teaching coping strategies can be a means to improve the QOL of women in societies where gender discrimination is prevalent.

Strengths and limitations of this study

- This one of few studies addressing empowerment of women performed within a society where gender discrimination is prevalent.

- The non-randomised design requires that multiple comparisons (between groups, within groups, effect sizes) must be taken into account while interpreting the results.

Kristenson, ${ }^{4}$ women generally have lower coping abilities compared with men. She explains this finding by referring to the fact that the socioeconomic position of women is less advantageous than that of men, which leads indirectly to fewer possibilities for adopting coping strategies. The position of Iranian women in society is particularly affected by the nature of patriarchal power and economic circumstances. There are many employment challenges and social inequalities in Iran affecting women's opportunities to access suitable jobs. ${ }^{5-7}$ Socioeconomic disadvantages are known to affect a wide range of aspects of health and mental well-being. ${ }^{8}$ Unsurprisingly, the health status of Iranian women is poorer than that of men. ${ }^{9}$ The prevalence of general psychiatric disorders has been found to be particularly high among women 
compared with men. ${ }^{10}$ It has also been noted that the prevalence of mental disorders is higher among Iranian women than women in Western countries, which has been explained by both biological factors and social inconveniences. ${ }^{11}$ For example, depression rates are higher among women compared with men in Iran $(4.3 \%$ vs $1.5 \%) .{ }^{12}$ In addition, between $70 \%$ and $80 \%$ of selfimmolation patients in Iran are women and marital conflict with a spouse or conflict with other family members are important causal factors in the process. ${ }^{13}$ Marriage is considered as an important source of both support and stress. Poor marital quality is associated with poor physical and psychological health. ${ }^{14}{ }^{15}$ The women are also at a higher risk for suicide compared with men in Iran; this has been explained by the fact that the social situation for Iranian women (ie, family problems, marriage and love, social stigma, pressure of high expectations and poverty and unemployment) creates more psychosocial pressures compared with men. ${ }^{16}$ The limited career possibilities outside the home also affect women's visions, and influence the woman's position in the family. ${ }^{17} 18$

From a general health perspective, there are reasons for strengthening the coping capacities of Iranian women. We organised psychosocial interventions aimed at teaching Iranian women coping strategies. Problem-focused coping strategies have been found to be more effective in situations where people have greater control (such as marriage and family); emotionfocused and meaning-focused strategies are more valuable when people have to deal with situations in which they have less control (eg, a national financial crisis). ${ }^{19}$ In line with Lazarus and Lazarus, ${ }^{20}$ our interventions were planned with the understanding that most problematic situations need these two strategies in parallel (ie, change problematic situations and regulate emotions simultaneously). Quality of life (QOL) was chosen as the primary end point for the interventions. The WHO Quality of Life (WHOQOL) Group defines QOL as 'individuals' perceptions of their position in life in the context of the culture and value systems in which they live and in relation to their goals, expectations, standards and concerns' (ref. ${ }^{21}$, p.5). The aim of the present study was to assess whether a psychosocial intervention teaching coping strategies to women can improve QOL in groups of Iranian women exposed to social pressures, represented by single mothers and newly married women.

\section{METHODS}

We used a quasi-experimental non-randomised groups design $^{22}$ involving two categories of Iranian women, each category represented by non-equivalent intervention and comparison groups. The intervention groups were invited to participate in a 7-month psychosocial intervention; the comparison groups were provided with treatment as usual by the social welfare services. QOL was used as the primary outcome measure in the analyses. Owing to lack of possibilities to control a randomised sampling procedure extended in time, the study had to rely on convenience samples. The study participants were recruited from programmes supplied by social welfare service organisations to single mothers and newly married women, respectively (figure 1). The WHOQOL-BREF instrument was used to measure QOL, comparing the scores for each intervention group before and after the intervention and with respect to their comparison group. The research design received ethical clearance according to the Helsinki declaration of research ethics from the research ethics board for social services (the single mothers' project ref. number 13870327 and the newly married women project ref. number 13870613).

\section{Participants}

\section{Single mothers}

Inclusion criteria were being a single mother, living in poverty, and having requested social assistance. The exclusion criteria were defined as having significant medical, mental or substance-abuse problems. A social welfare service organisation agreed to identify 26 single mothers contacting their offices and fulfilling the study inclusion and exclusion criteria. The first author arranged a meeting with these women, and explained the procedure and aims of the study. The first 16 of the women identified were invited to participate in an intervention group and the 10 remaining women were invited to participate in a comparison group provided traditional social welfare services. One woman invited to the intervention group declined participation in the study. All women signed a consent form (table 1).

\section{Newly married women}

The inclusion criteria for this group were to be newly married (first marriage, less than 5 years married, and no children) and having contacted a social work office. Exclusion criteria included having significant medical, mental or substance-abuse problems. In Iran, financial support from the social welfare services is available to newly married couples in need. To access such support, it is necessary to participate in at least one family educational programme. A social welfare service organisation agreed to identify 40 women eligible for the study. Thirty of these women agreed to participate in an information session. Having been informed about the study, 10 women agreed to participate in an intervention group and 9 women agreed to participate in a comparison group provided with traditional social welfare services. All women signed a consent form (table 1).

\section{Intervention procedure}

The single mother project started in May 2008 and ended in November 2008 and the newly married women project started in July 2008 and ended in February 2009. The intervention included private and group sessions. The Rahyab problem-solving model ${ }^{23}$ was used in both 
Figure 1 Flowchart for recruitment of participants to intervention and comparison groups.

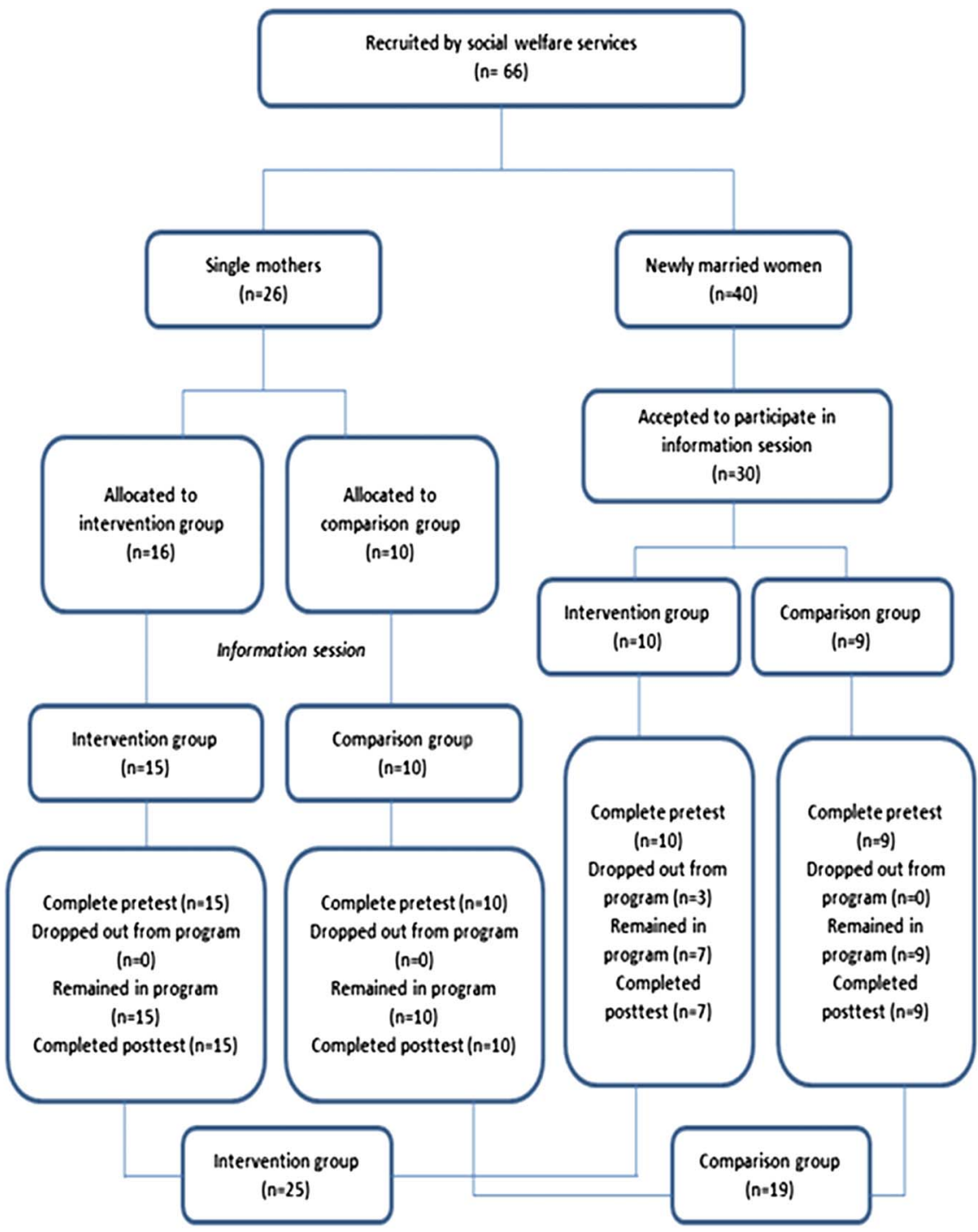

types of sessions. The Rahyab model is summarised in a conceptual chart (see online supplementary table S1), which is used in interactions with clients, linking the development of specific personal capacities with different problem-solving approaches and means for mobilising resources in the environment. Group sessions were arranged aimed at teaching the clients coping strategies by cognitive problem solving and emotion regulation. These sessions were offered once a week. In total, 19 group sessions were provided for each of the projects. In these sessions, the participants used the Rahyab model to solve fictional problems and scenarios that were suggested by the participants. Examples of topics addressed during the sessions include life skills; decision-making and problem-solving, creative and critical thinking, effective communication, interpersonal relationship, selfawareness and coping with emotion and stress. A form was distributed at the beginning of each group session, and participants had 15-20 min to write down what they thought about that problem or scenario. The participants then presented their ideas, based on what each had written, and a discussion took place.
Private sessions were devoted to discussion of the participants' private lives and problems. The Rahyab model was systematically applied in steps in a dialogue between the social worker and the participant, focusing on a concrete problem that the participant chose to discuss. Each step addressed a specific coping ability. In these sessions, the participant learned to organise her feelings and thoughts through storytelling and discussing desirable changes (steps 1 and 2). The dialogue continued with the aim of finding several possible alternatives for action (step 3). In this step, the social worker provided suggestions but the participant had to choose the best possible option. A plan of action was then formulated on the basis of that option. Participants were encouraged to take a paper and pen and continue to think and write through the steps of the model at home.

\section{Data collection}

The primary outcome measure was the participants' level of QOL as measured by the WHOQOL-BREF, the short form of the WHOQOL-100 instrument developed by the WHO. The Iranian version of the 


\begin{tabular}{|c|c|c|c|c|c|c|}
\hline \multirow[b]{2}{*}{$\begin{array}{l}\text { Sociodemographic } \\
\text { characteristics }\end{array}$} & \multicolumn{2}{|c|}{ Single mothers } & \multicolumn{2}{|c|}{ Newly married women } & \multicolumn{2}{|l|}{ Total } \\
\hline & $\begin{array}{l}\text { Intervention } \\
\text { group }(n=15)\end{array}$ & $\begin{array}{l}\text { Comparison } \\
\text { group }(n=10)\end{array}$ & $\begin{array}{l}\text { Intervention } \\
\text { group }(n=10)\end{array}$ & $\begin{array}{l}\text { Comparison } \\
\text { group }(n=9)\end{array}$ & $\begin{array}{l}\text { Intervention } \\
\text { group }(n=25)\end{array}$ & $\begin{array}{l}\text { Comparison } \\
\text { group }(n=19)\end{array}$ \\
\hline \multicolumn{7}{|l|}{ Age (years) } \\
\hline $20-29$ & 4 & 2 & 10 & 9 & 14 & 11 \\
\hline 30-39 & 7 & 6 & 0 & 0 & 7 & 6 \\
\hline $40-49$ & 4 & 2 & 0 & 0 & 4 & 2 \\
\hline \multicolumn{7}{|l|}{ Education } \\
\hline Primary school $\leq 5$ years & 5 & 3 & 0 & 0 & 5 & 3 \\
\hline Primary school $7-8$ years & 5 & 3 & 0 & 0 & 5 & 3 \\
\hline High school diploma & 5 & 4 & 1 & 0 & 6 & 4 \\
\hline Undergraduate study & 0 & 0 & 9 & 9 & 9 & 9 \\
\hline \multicolumn{7}{|l|}{ Work situation } \\
\hline No employment & 6 & 6 & 5 & 4 & 11 & 10 \\
\hline $\begin{array}{l}\text { Part-time or temporary } \\
\text { employment }\end{array}$ & 9 & 4 & 0 & 0 & 9 & 4 \\
\hline Full employment & 0 & 0 & 5 & 5 & 5 & 5 \\
\hline \multicolumn{7}{|l|}{ Number of children } \\
\hline 0 & 0 & 0 & 10 & 9 & 10 & 9 \\
\hline $1-2$ & 8 & 7 & 0 & 0 & 8 & 7 \\
\hline 3 & 7 & 3 & 0 & 0 & 7 & 3 \\
\hline
\end{tabular}

WHOQOL-BREF has recently been validated. ${ }^{24} 25$ The WHOQOL-BREF is a 26-item instrument consisting of four domains: physical health (7 items), psychological health (6 items), social relationships (3 items), environmental health (8 items) as well as two overall ratings of QOL and general health. There is no overall score. The physical health domain includes items on mobility, daily activities, functional capacity and energy, pain and sleep. The psychological domain measures self-image, negative thoughts, positive attitudes, self-esteem, mentality, learning ability, memory and concentration, religion and mental status. The social relationships domain contains questions on personal relationships, social support and sex life. The environmental health domain covers issues related to financial resources, safety, health and social services, living in the physical environment, opportunities to acquire new skills and knowledge, recreation, general environment (noise, air pollution, etc) and transportation. All scores were transformed to reflect 4-20 for each domain with higher scores corresponding to a better QOL. ${ }^{21}$

We distributed the WHOQOL-BREF questionnaire to the intervention and comparison groups before starting the project (preintervention) and immediately after the project (postintervention). The women scored the instrument by themselves.

\section{Data analysis}

We used SPSS statistics V.19.0 to apply non-parametric tests for comparing results in WHOQOL scores between groups and within each group $(95 \% \mathrm{CI})$. The analyses were initially performed separately for each project and thereafter on the data from both projects combined.
Only the data from women who had completed the prescribed treatments were included in the analysis. First, we used the Mann-Whitney test to compare results between the intervention and comparison groups, then we used the Wilcoxon test and compared the pretest and post-test WHOQOL scores within each group. In addition to significance tests, we calculated effect sizes for non-parametric data according to Cohen's formula $\mathrm{r}=\mathrm{z} / \sqrt{ } \mathrm{N}^{\prime}{ }^{26}$ We computed effect size calculations in the four specific domains, and for the two overall perceptions of self-rated health and QOL in the intervention and comparison groups. Cohen's guidelines for interpretation of $r$ suggest that the limit for a large effect size is 0.5 , for a medium effect is 0.3 and for a small effect is 0.1 . Effect sizes create a more generally interpretable, quantitative description of the size of an effect. ${ }^{27}$

\section{RESULTS}

\section{Single mothers}

The study completion rate was $100 \%$ in the single mother category. At the pretest stage, the intervention group scored higher on overall self-rated health than the comparison group $(p<0.05)$. At the post-test stage, the scores in the intervention group on overall self-rated QOL were higher than those in the comparison group $(\mathrm{p}<0.05$; table 2$)$.

After the intervention, there were statistically significant increases in WHOQOL-BREF scores measuring physical health $(\mathrm{p}<0.05)$, psychological health $(\mathrm{p}<0.01)$, social relationships $(p<0.05)$ and overall perception of QOL $(p<0.01)$ in the intervention group. No statistically significant difference was found for environmental health and overall self-rated health. In the comparison 


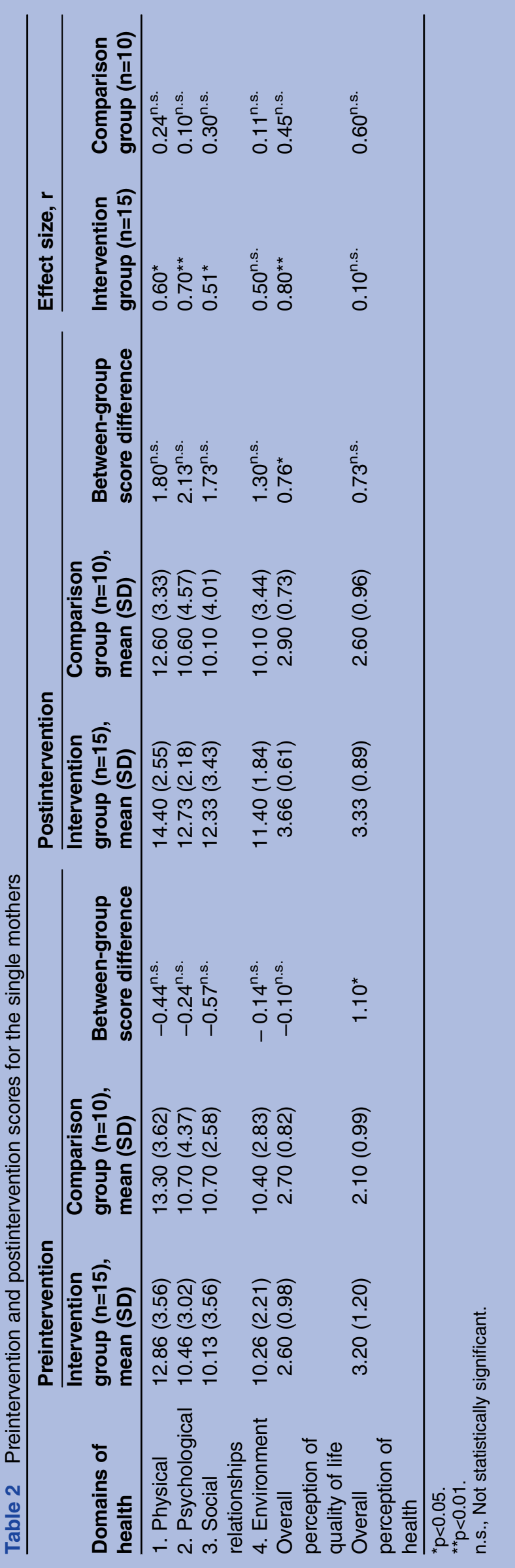

group, no statistically significant change was observed for any domain or overall perception. Large and statistically significant effect sizes were observed in most WHOQOL-BREF domains except environmental health and overall self-rated health. In the comparison group, the effect sizes were not statistically significant (table 2).

\section{Newly married women}

Seventy per cent of the newly married women completed the study. Owing to personal issues (eg, health problems during pregnancy), three of the women in the intervention group did not complete their participation in the individual and group sessions. The data for these women were excluded from further analysis.

At the pretest stage, the scores for the participants in the intervention group for the physical health $(\mathrm{p}<0.05)$ and social relationship $(\mathrm{p}<0.05)$ domains were lower compared with those of the comparison group (table 3). At the post-test stage, the intervention group had higher scores in the environmental health domain $(\mathrm{p}<0.01)$ than the comparison group.

In the intervention group, there were statistically significant increases in postintervention scores in the physical health $(p<0.05)$, psychological health $(p<0.05)$ and environmental health $(\mathrm{p}<0.05)$ domains. No statistically significant difference was found in the social relationships domain or regarding overall perceptions of QOL or health. No statistically significant changes were observed in the comparison group. Large and statistically significant effect sizes were observed in the intervention group in the physical health, psychological health and environmental health domains. Large but not statistically significant effect sizes were observed in the social relationships domain and for overall perceptions of QOL and health. In the comparison group, the effect sizes were small or medium and not statistically significant (table 3).

\section{Aggregated intervention and comparison groups}

On aggregate, $88 \%$ of the women having agreed to participate completed the study. At the pretest and post-test stages, no statistically significant differences were observed between the aggregated intervention and comparison groups (table 4). In the aggregated intervention group, statistically significant increases in scores were observed after the intervention for all WHOQOL-BREF domains (physical health $(\mathrm{p} \leq 0.001)$, psychological health $(\mathrm{p} \leq 0.001)$, social relationships $(\mathrm{p} \leq 0.01)$, environmental health $(\mathrm{p} \leq 0.01)$ and the overall perception of QOL $(p \leq 0.001)$. No statistically significant change was found in overall self-rated health in this group. In the aggregated comparison group, no statistically significant changes were observed. Large and statistically significant effect sizes were observed in the intervention group in all WHOQOL-BREF domains and the overall perception of QOL (table 4). The effect size for overall self-rated health was between small and medium and not statistically significant. In 
Table 3 Preintervention and postintervention scores for the newly married women

\begin{tabular}{|c|c|c|c|c|c|c|c|c|}
\hline \multirow[b]{2}{*}{$\begin{array}{l}\text { Domains of } \\
\text { health }\end{array}$} & \multicolumn{3}{|c|}{ Preintervention } & \multicolumn{3}{|c|}{ Postintervention } & \multicolumn{2}{|l|}{ Effect size, $r$} \\
\hline & $\begin{array}{l}\text { Intervention } \\
\text { group }(n=7), \\
\text { mean }(S D)\end{array}$ & $\begin{array}{l}\text { Comparison } \\
\text { group }(n=9), \\
\text { mean }(S D)\end{array}$ & $\begin{array}{l}\text { Between-group } \\
\text { score difference }\end{array}$ & $\begin{array}{l}\text { Intervention } \\
\text { group }(n=7) \text {, } \\
\text { mean }(S D)\end{array}$ & $\begin{array}{l}\text { Comparison } \\
\text { group }(n=9), \\
\text { mean }(S D)\end{array}$ & $\begin{array}{l}\text { Between-group } \\
\text { score difference }\end{array}$ & $\begin{array}{l}\text { Intervention } \\
\text { group }(n=7)\end{array}$ & $\begin{array}{l}\text { Comparison } \\
\text { group }(n=9)\end{array}$ \\
\hline 1. Physical & $12.85(1.95)$ & $15.55(2.24)$ & $-2.70^{*}$ & $16.57(1.39)$ & $15.33(2.73)$ & $1.24^{\text {n.s. }}$ & $0.90^{*}$ & $0.19^{\text {n.s. }}$ \\
\hline 2. Psychological & $13.14(1.95)$ & 14.66 (1.32) & $-1.52^{\text {n.s. }}$ & $14.57(1.39)$ & $14.22(2.22)$ & $0.35^{\text {n.s. }}$ & $0.86^{\star}$ & $0.29^{\text {n.s. }}$ \\
\hline $\begin{array}{l}\text { 3. Social } \\
\text { relationships }\end{array}$ & $13.28(1.70)$ & $16.00(1.73)$ & $-2.72^{\star}$ & $14.71(2.05)$ & $16.33(1.58)$ & $-1.62^{\text {n.s. }}$ & $0.57^{\text {n.s. }}$ & $0.32^{\text {n.s. }}$ \\
\hline 4. Environment & $13.85(1.77)$ & $13.33(2.44)$ & $0.52^{\text {n.s. }}$ & $15.85(1.06)$ & 13.55 (1.66) & $2.30^{\star \star}$ & $0.78^{*}$ & $0.17^{\text {n.s. }}$ \\
\hline $\begin{array}{l}\text { Overall } \\
\text { perception of } \\
\text { quality of life }\end{array}$ & $3.57(0.97)$ & $4.11(0.60)$ & $-0.54^{\text {n.s. }}$ & $4.28(0.48)$ & $3.88(0.60)$ & $0.40^{\text {n.s. }}$ & $0.62^{\text {n.s. }}$ & $0.33^{\text {n.s. }}$ \\
\hline $\begin{array}{l}\text { Overall } \\
\text { perception of } \\
\text { health }\end{array}$ & $3.28(1.25)$ & $4.11(0.33)$ & $-0.83^{\text {n.s. }}$ & $4.00(0.57)$ & $4.11(0.60)$ & $-0.11^{\text {n.s. }}$ & $0.62^{\text {n.s. }}$ & $0.00^{\text {n.s. }}$ \\
\hline
\end{tabular}

Table 4 Preintervention and postintervention scores for the aggregated intervention and comparison groups

\begin{tabular}{|c|c|c|c|c|c|c|c|c|}
\hline \multirow[b]{2}{*}{$\begin{array}{l}\text { Domains of } \\
\text { health }\end{array}$} & \multicolumn{3}{|c|}{ Preintervention } & \multicolumn{3}{|c|}{ Postintervention } & \multicolumn{2}{|l|}{ Effect size, $r$} \\
\hline & $\begin{array}{l}\text { Intervention } \\
\text { group }(n=22), \\
\text { mean (SD) }\end{array}$ & $\begin{array}{l}\text { Comparison } \\
\text { group }(n=19), \\
\text { mean (SD) }\end{array}$ & $\begin{array}{l}\text { Between-group } \\
\text { score difference }\end{array}$ & $\begin{array}{l}\text { Intervention } \\
\text { group }(n=22), \\
\text { mean (SD) }\end{array}$ & $\begin{array}{l}\text { Comparison } \\
\text { group }(n=19), \\
\text { mean (SD) }\end{array}$ & $\begin{array}{l}\text { Between-group } \\
\text { score difference }\end{array}$ & $\begin{array}{l}\text { Intervention } \\
\text { group }(n=22)\end{array}$ & $\begin{array}{l}\text { Comparison } \\
\text { group }(n=19)\end{array}$ \\
\hline 1. Physical & $12.86(3.09)$ & $14.36(3.18)$ & $-1.50^{\text {n.s. }}$ & $15.09(2.44)$ & 13.89 (3.29) & $1.20^{\text {n.s. }}$ & $0.68^{\star \star \star}$ & $0.20^{\text {n.s. }}$ \\
\hline 2. Psychological & 11.31 (2.96) & $12.57(3.80)$ & $-1.25^{\text {n.s. }}$ & $13.31(2.12)$ & $12.31(4.01)$ & $1.00^{\text {n.s. }}$ & $0.72^{\star \star \star}$ & $0.17^{\text {n.s. }}$ \\
\hline $\begin{array}{l}\text { 3. Social } \\
\text { relationships }\end{array}$ & $11.13(3.39)$ & $13.21(3.47)$ & $-2.08^{\text {n.s. }}$ & 13.09 (3.22) & $13.05(4.40)$ & $0.04^{\text {n.s. }}$ & $0.52^{\star \star}$ & $0.07^{\text {n.s. }}$ \\
\hline 4. Environment & $11.40(2.66)$ & 11.78 (2.99) & $-0.38^{\text {n.s. }}$ & $12.81(2.66)$ & $11.73(3.21)$ & $1.08^{\text {n.s. }}$ & $0.55^{\star \star}$ & $0.02^{\text {n.s. }}$ \\
\hline $\begin{array}{l}\text { Overall } \\
\text { perception of } \\
\text { quality of life }\end{array}$ & $2.90(1.06)$ & $3.36(1.01)$ & $-0.46^{\text {n.s. }}$ & $3.86(0.63)$ & $3.36(0.83)$ & $0.50^{\text {n.s. }}$ & $0.72^{* \star \star}$ & $0.00^{\text {n.s. }}$ \\
\hline $\begin{array}{l}\text { Overall } \\
\text { perception of } \\
\text { health }\end{array}$ & 3.22 (1.19) & $3.05(1.26)$ & $0.17^{\text {n.s. }}$ & $3.54(0.85)$ & $3.31(1.10)$ & $0.23^{\text {n.s. }}$ & $0.20^{\text {n.s. }}$ & $0.38^{\text {n.s. }}$ \\
\hline \multicolumn{9}{|c|}{$\begin{array}{l}{ }^{*} p<0.05 \\
{ }^{* *} p \leq 0.01 \\
\text { n.s } p \leq 0.001 . \\
\text { n.s., Not statistically significant. }\end{array}$} \\
\hline
\end{tabular}


the aggregated comparison group, the effect sizes were small or medium and not statistically significant.

\section{DISCUSSION}

This study provides provisional support for that teaching of coping strategies can be a means to improve the QOL of women in societies where gender discrimination is prevalent. The aggregated data from the two categories of Iranian women provided with the intervention showed significant improvement in overall self-rated QOL and in the particular domain of self-rated health. The effect size on overall self-rated health in the aggregated intervention group was not statistically significant. One explanation for this finding could be that as a result of the non-randomised study design, already healthy women by various selection mechanisms were allocated to the more demanding intervention groups. This interpretation is supported by the fact that the pretest scores on overall self-rated health in the aggregated intervention group were higher than in comparison group and higher than in the other WHOQOL-BREF domains. When the categories of women and instrument domains were considered separately, we found no statistically significant postintervention change in the social relationships domain among the newly married women in the intervention group and no change in the environment domain among the single mothers. Recent re-evaluation of the Iranian version of the WHOQOL-BREF has shown an unsatisfactory reliability of the social relationship domain, which may explain why no change was recorded in this domain. According to the Iranian researchers, re-evaluation studies from other countries have reported similar results, implying that this domain of the WHOQOL-BREF requires a general revision. ${ }^{24} 25$ Regarding the scores for the single mothers in the environmental domain, a positive trend not reaching statistical significance could be observed. However, single mothers may be more likely to face structural and environmental problems that are resistant to change efforts.

One possible explanation for the study outcomes is that both problem-solving and emotion-control coping strategies were supported in the intervention model. Pearlin et $a t^{28}$ (p.340) refer to the role of mastery in the stresscoping process, defining it as 'the extent to which people see themselves as being in control of the forces that importantly affect their lives'. However, not all problems in life can be mastered, but the problems can often be managed, that is, people can learn to accept and live with existing troubling circumstances. ${ }^{20}$ This standpoint applies to the situation for Iranian women in the present study. These women, particularly in the single mothers' project, faced severe structural problems in their day-to-day lives. Although there were few opportunities to realise several of the desirable changes in their life situations, the women still used the intervention to increase their QOL and influence several aspects of their self-rated health. This may be because they gained insight and personal empowerment despite persisting hardships. ${ }^{29}{ }^{30}$ From this aspect, the findings of this study conducted in Iran correspond with results from previous studies of coping in relation to QOL and health. ${ }^{1} 4131931$ The observations in our study are also understandable in light of Antonovsky's salutogenic health model based on a sense of coherence, ${ }^{32-34}$ that is, that individuals accomplish resilience by using general psychological resources to conceptualise the world as organised and understandable. Further research is necessary to evaluate the association between coping strategies with health and QOL in applying the psychosocial interventions.

From an intervention design perspective, the model used in this study is similar to Frisch's model for QOL therapy. ${ }^{35}$ The latter model is based on the CASIO framework for QOL and involves both problem-solving and emotional support components, that is, steps and methods ranging from influencing circumstances to changing priorities and boosting satisfaction in other areas not previously considered. The role of emotional control in improvement of QOL among individuals who face difficult circumstances that they are not able to change in specific areas of life has been demonstrated in other contexts, such as management of chronic disease. For instance, from a study of patients with kidney failure ${ }^{36}$ it was reported that central mediators of effect in QOL therapy were improvement in social intimacy and reduction of psychological distress. Both QOL therapy and the present intervention based on the Rahyab model emphasise the individual's perceptions and interpretations, goal-setting and value clarifications. However, in contrast to QOL therapy, group sessions were a central part of the study intervention. Group sessions are important in interventions aimed at improving women's life situations and creating learning spaces where women can gather insight into feelings of sympathy and empathy while dealing with difficult structural problems. ${ }^{29} 30$ The group sessions probably also mediated effects in domains other than that of social relationships. Nonetheless, the design of interventions for maintenance of QOL in pressing life situations remains an important area for future studies in health promotion.

There are several factors that must be taken into account when interpreting the results of this study. A fully randomised study design could not be realised because only a limited number of participants could be included in the intervention programme owing to scarcity of resources and because distribution of information about a study addressing strengthening of coping capacities of women was sensitive in the implementation context. The number of participants invited could therefore not be predetermined using power calculations and the women in the newly married category could not be randomly allocated to the intervention and comparison groups. This implies that neither type 2 errors based on insufficient power nor type 1 biases owing to paticipant's self-selection can be ruled out. The analyses of the pretest ratings in the intervention and comparison groups in the two projects also showed some statistically 
significant differences (in the single mothers' project regarding overall self-rated health and in the newly married women project in the physical health and the social relationships domains). Also, non-participation was higher among the newly married women than in the single mothers' category. This difference can be explained by that the latter group was burdened by more severe problems and was more willing to participate in a programme that they envisioned could supply them with more extensive support. The quasi-experimental non-equivalent groups design therefore requires that multiple comparisons (between groups, within groups, effect sizes) must be taken into account when interpreting the results of the study. In addition, the study end point was defined as the end of the intervention period, implying that the lasting effects of the intervention were not recorded. Furthermore, it is important to take into account both participants' and therapists' personal characteristics in the evaluation of therapeutic interventions. ${ }^{37}$ The women who agreed to participate might have been more amenable to QOL interventions, so they may have been more likely to report therapeutic gains than those who chose not to participate. Kendall ${ }^{38}$ (p. 4) expands on this point when he writes that 'empirical evaluation of therapy is a step in the right direction, but it does not guarantee that empirically evaluated treatments will be effective when applied by different therapists'. It must also be taken into account that neither the practitioners nor women, for logical reasons, were blinded for the intervention. However, the women scored the instruments by themselves, which should have reduced, although not eliminated, the nonblinding influence from the therapists. Therefore, before wider distribution, the intervention model should be evaluated in studies involving social workers with different training and backgrounds.

\section{CONCLUSIONS}

This quasi-experimental study of an intervention teaching a combined problem-solving and emotional-control coping strategy to Iranian women showed large postintervention effect sizes on QOL scores among women provided with the intervention. The scores in a comparison group provided with treatment as usual showed no statistically significant changes. The results are encouraging but require reproduction in larger studies with a more rigorous design and longer time frame for follow-up before the intervention model can be recommended for widespread distribution.

Contributors HAR, TT, AM and KL conceived and designed the study. HAR collected the data. HAR and TT analysed the data. HAR and TT wrote the paper. $A M$ and $K L$ revised the manuscript and provided intellectual content. $\mathrm{HAR}, \mathrm{TT}, \mathrm{AM}$ and $\mathrm{KL}$ participated in final approval of the version to be published. TT is the guarantor of the content.

Funding This research received no specific grant from any funding agency in the public, commercial or not-for-profit sectors. The study was supported by faculty funding from Linköping Universitet. The funder had no role in study design, data collection and analysis, decision to publish, or preparation of the manuscript.

\section{Competing interests None.}

Ethics approval The research ethics board for social services in Mashhad (the single mothers' project ref. number 13870327 and the newly married women project ref. number 13870613).

Provenance and peer review Not commissioned; externally peer reviewed.

Data sharing statement No additional data are available.

\section{REFERENCES}

1. Braun-Lewensohn O, Sagy S, Roth G. Coping strategies as mediators of the relationship between sense of coherence and stress reactions: Israeli adolescents under missile attacks. Anxiety Stress Coping 2011;24:327-41.

2. Folkman S, Moskowitz JT. Coping: pitfalls and promise. Annu Rev Psychol 2004;55:745-74.

3. Somerfield MR, McCrae RR. Stress and coping research; methodological challenges, theoretical advances, and clinical applications. Am Psychol 2000;55:620-5.

4. Kristenson M. Socio-economic position and health: the role of coping. In: Siegrist J, Marmot M, eds. Social inequalities in health. New York: Oxford University Press, 2006:127-51.

5. Shirazi F. Information and communication technology and women empowerment in Iran. Telematics Inform 2011;29:45-55.

6. Moghadam VM. Urbanization and women's citizenship in the Middle East. Brown J World Affairs 2010;17:19-34.

7. Berkovitch N, Moghadam VM. Middle East politics and women's collective action: challenging the status quo. Soc Pol 1999;6:273-91.

8. Siegrist J, Marmot M. Social inequalities in health: basic facts. In: Siegrist JMarmot M, eds. Social inequalities in health. New York: Oxford University Press, 2006:1-25.

9. Montazeri A, Goshtasebi A, Vahdaninia M, et al. The Short Form Health Survey (SF-36): translation and validation study of the Iranian version. Qual Life Res 2005;14:875-82.

10. Mohamadi MR, Davidian H, Noorbala AA, et al. An epidemiological survey of psychiatric disorders in Iran. Clin Pract Epidemiol Mental Health 2005;1:16.

11. Noorbala AA, Yazdi SA Bagheri, Yasamy MT, et al. Mental health survey of the adult population in Iran. $\mathrm{Br} J$ Psychiatry 2004;184:70-3.

12. Dejman M, Forouzan A Setareh, Assari S, et al. How Iranian lay people in three ethnic groups conceptualize a case of a depressed woman: an explanatory model. Ethn Health 2010;15:475-93.

13. Ahmadi A, Mohammadi R, Schwebel DC, et al. Familial risk factors for self-immolation: a case-control study. J Womens Health 2009;18:1025-31.

14. Umberson D, Montez J Karas. Social relationships and health: a flashpoint for health policy. J Health Soc Behav 2010;51:s54-66.

15. Walen HR, Lachman ME. Social support and strain from partner, family, and friends: costs and benefits for men and women in adulthood. J Soc Pers Relat 2000;17:5-30.

16. Keyvanara M, Haghshenas A. The sociocultural contexts of attempting suicide among women in Iran. Health Care Women Int 2010;31:771-83.

17. Crocco MS, Pervez N, Katz M. At the crossroads of the world: women of the Middle East. Soc Stud 2009;100:107-14.

18. Akhter R, Ward KB. Globalization and gender equality: a critical analysis of women's empowerment in the global economy. Adv Gender Res 2009;13:141-73.

19. Thoits PA. Compensatory coping with stressors. In: Avison WR, Aneshensel CSSchieman S, et al., eds. Advances in the conceptualization of the stress process: essay in honor of Leonard I. Pearlin. New York: Springer, 2010:23-34.

20. Lazarus RS, Lazarus BN. Coping with aging. New York: Oxford University Press, 2006.

21. World Health Organization (WHO). WHOQOL-BREF, introduction, administration, scoring \& generic version of the assessment. Geneva: WHO, 1996. http://www.who.int/mental_health/media/en/ 76.pdf (accessed 9 Jul 2012).

22. Shadish WR, Cook TD, Campbell DT. Experimental and quasi-experimental designs for generalized causal inference. Chicago, IL: Rand McNally, 2001.

23. Moula A. Population Based Empowerment Practice in Immigrant Communities. Saarbrucken: Lambert Academic Publisher, 2010. 
24. Jahanlou AS, Karami N Alishan. WHO quality of life-BREF 26 questionnaire: reliability and validity of the Persian version and compare it with Iranian diabetics quality of life questionnaire in diabetic patients. Prim Care Diabetes 2011:5:103-7.

25. Nedjat S, Montazeri A, Holakouie K, et al. Psychometric properties of the Iranian interview-administered version of the World Health Organization's Quality of Life Questionnaire (WHOQOL-BREF): a population-based study. BMC Health Serv Res 2008;8:61.

26. Cohen J. Statistical power analysis for the behavioral sciences. 2nd edn. Hillsdale, NJ: Erlbaum, 1988.

27. Fritz CO, Morris PE, Richler JJ. Effect size estimates: current use, calculations, and interpretation. J Exp Psychol Gen 2011;14:2-18.

28. Pearlin LI, Menaghan EG, Lieberman MA, et al. The stress process. $J$ Health Soc Behav 1981;22:337-56.

29. Addelyan Rasi H, Moula A, Puddephatt AJ, et al. Empowering single mothers in Iran: applying a problem-solving model in learning groups to develop participants' capacity to improve their lives. Br J Soc Work. Published Online First: 1 March 2012. doi:10.1093/bjsw/bcs009

30. Addelyan Rasi $\mathrm{H}$, Moula A, Puddephatt AJ, et al. Empowering newly married women in Iran: a new method of social work intervention that uses a client-directed problem-solving model in both group and individual sessions. Qualitative Soc Work. Published Online First: 18 September 2012. doi: $10.1177 / 1473325012458310$

31. Heppner PP. Expanding the conceptualization and measurement of applied problem solving and coping: from stages to dimensions to the almost forgotten cultural context. Am Psychol 2008;63:805-16.

32. Antonovsky A. Health, stress, and coping. San Francisco, CA: Jossey-Bass, 1979.

33. Antonovsky A. Unraveling the mystery of health. How people manage stress and stay well. San Francisco, CA: Jossey-Bass, 1987.

34. Antonovsky A. The structure and properties of the sense of coherence scale. Soc Sci Med 1993;36:725-33.

35. Frisch MB. Quality of life therapy and assessment in health care. Clin Psychol Sci Pract 1998;5:19-40.

36. Rodrigue JR, Mandelbrot DA, Pavlakis M. A psychological intervention to improve quality of life and reduce psychological distress in adults awaiting kidney transplantation. Nephrol Dial Transplant 2010;26:709-15.

37. Garfield SL. Some comments on empirically supported treatments. $J$ Consult Clin Psychol 1998;66:121-5.

38. Kendall PC. Empirically supported psychological therapies. J Consult Clin Psychol 1998;66:3-6. 